\title{
La pericia médico-legal en los casos de responsabilidad médica.
}

\author{
The medicolegal expertise in cases of medical \\ negligence.
}

IV JORNADAS ANDALUZAS SOBRE VALORACIÓN DEL DAÑO CORPORAL Sevilla, mayo-junio 2001

\section{J.L. Romero Palanco ${ }^{1}$}

\section{RESUMEN}

Tras una breve introducción dedicada al análisis de las motivaciones que parecen conducir a los casos de demandas judiciales contra los médicos, se hace un estudio pormenorizado de la peritación médico-legal. En esta parte es objeto de análisis la nueva dirección impresa al método médico-forense, pasando después a formular diversas consideraciones en torno a las cualidades que debe reunir el perito médico. Se hace una revisión del marco normativo en el que se ha de desarrollar la peritación médica, la cual es analizada bajo la perspectiva de la Ley de Enjuiciamiento Criminal y de la nueva Ley de Enjuiciamiento Civil. Finalmente, se dictan pautas de carácter práctico sobre la elaboración y estructura del informe pericial en los casos que se vienen analizando.

Palabras clave: Medicina Forense. Responsabilidad profesional médica. Pericia médico-legal.

\section{ABSTRACT}

After a brief introduction dedicated to the analysis of the reasons behind lawsuits against doctors, a detailed study of medical - legal work is realized. In this part the published guidelines regarding medical forensic methodology are analysed, followed by comments on the essential qualities that are required in the forensic expert.

The legal framework within which forensic work is carried out is also reviewed. Such work is analysed in the light of the law of criminal prosecution and the new law of civil prosecution. Finally, practical guidelines are given on the elaboration and structure of expert reports in the cases that are analysed.

Key words: Forensic Medicine. Malpractice professional. Medical-forensic methodology.

Correspondencia:José Luis Romero Palanco. Departamento de Medicina Legal y Toxicología. Facultad de Medicina. Plaza Fragela s/n. 11003 CÁDIZ. Tfno.: 956015190 Fax: 9560151 91. E-mail: joseluis.romero@uca.es

\footnotetext{
1 Médico Especialista en Medicina Legal y Forense. Médico Forense (excedencia voluntaria). Catedrático de Medicina Legal y Forense. Facultad de Medicina. Universidad de Cádiz
} 


\section{I.- DEMANDAS JUDICIALES CONTRA MÉDICOS.}

Ya en 1923, LUCAS CHAMPIONIERE afirmaba que "el problema de la responsabilidad médica es cada día más grave y angustiante y preocupa con toda razón a todos los médicos", añadiendo que "si no se quiere cortar la iniciativa benefactora que puede curar a los enfermos, interesa mucho proteger al médico honesto y consciente contra las persecuciones injustas".

Esta aseveración resulta hoy, casi ochenta años después, de una rabiosa actualidad, dado el elevado y cada vez más creciente número de demandas que se presentan en los Tribunales contra profesionales de la Medicina y contra las administraciones sanitarias, habiéndose incrementado estas durante la década de los años 80 y 90 casi en progresión geométrica, lo que nos permitiría afirmar que nos encontramos ante una verdadera "litigation disease" (Fiebre de las demandas), como la que afectó a la sociedad norteamericana tras la finalización de la Segunda Guerra Mundial y que todavía hoy no ha remitido.

Por lo que se refiere al número exacto de demandas contra médicos en nuestro país, pese a que no se dispone de datos estadísticos completos, se ha estimado por algunos estudiosos de esta particular cuestión que uno de cada cien facultativos es objeto de reclamación ante los Tribunales (MARTíNEZ-PEREDA RODRÍGUEZ, 1994) [I], resultando sumamente elocuente en relación con la gravedad de las cifras y, sobre todo, con la evolución de las mismas, el hecho de que entre 1970 y 1980 no llegaron a cincuenta las reclamaciones contra médicos, en tanto que solo en 1987 se produjeron 127 denuncias. Recuerda dicho autor que desde el año 1986, I 275 de los 19.000 facultativos inscritos en el Colegio Oficial de Médicos de Barcelona han sufrido alguna reclamación relacionada con su práctica asistencial. De otra parte, en una publicación posterior, MARTíNEZ-PEREDA RODRÍGUEZ (1995) [2] recoge que en el año 199| más de doscientos médicos del Insalud fueron denunciados y que en 1992 el número de denuncias alcanzó a más de trescientos médicos. En Barcelona, según datos del Colegio Oficial de Médicos, que reproducen PUJOL ROBINAT y PUIG BAUSILI [3], las denuncias han ido aumentando progresivamente desde 1986, con 89 denuncias y 109 médicos denunciados, hasta llegar al año 1991, con 305 denuncias y 436 médicos denunciados.

Ha de precisarse, no obstante, que las denuncias contra los médicos no se producen con carácter indiscriminado, sino que suelen tener una mayor incidencia sobre aquellas especialidades médicas, cuyo ejercicio implica un mayor número de riesgos. Atendiendo al número de casos que han llegado hasta el Tribunal Supremo, en vía penal, son los cirujanos los que presentan mayor número de casos ( I $8.86 \%$ ), seguidos de los anestesistas ( $13.30 \%$ ) y de los ginecólogos ( I $2.26 \%$ ), según MARTÍNEZ PEREDA ( 1995), cuyas cifras vienen a coincidir con las que se ofrecen en otros países del mundo occidental. Por el contrario, especialidades como la Psiquiatría tienen una baja incidencia, dando buena prueba de ello el hecho de que entre 1974 y 1978 solo un $0.3 \%$ del total de demandas contra médicos en los Estados Unidos se presentaron contra psiquiatras (SLAWSON y GUGGENHEIN) [4].

Por lo que se refiere a nuestro país, y en relación con la citada especialidad, señala CARRASCO GÓMEZ [5], que en la encuesta por él realizada, el I8. I \% de los psiquíatras habían tenido algún tipo de reclamación judicial, si bien la totalidad de las actuaciones judiciales terminaron con la absolución o archivadas. Pese al valor relativo que cabe asignarle a las cifras ofrecidas, puede afirmarse, en términos generales, que el índice de errores médicos producidos y que llegan a los Tribunales, es extraordinariamente bajo si se le compara con el altísimo número de actos médicos que a diario se llevan a cabo. 
Es muy posible, a pesar de que no deja ser paradójico, que uno de los factores que inducen a la presentación de mayor número de demandas corre parejo con los avances de la Medicina en general, dado el mayor riesgo que representan algunas técnicas incorporadas al quehacer del médico, y ello, sin que lleguemos a compartir la afirmación de IVAN ILLICH [6], según el cual "la medicina institucionalizada ha llegado a convertirse en una grave amenaza para la salud". Por el contrario, estimamos que son otros muchos los factores que pueden influir a la hora de adoptar una tal determinación, entre los que podríamos citar a los siguientes:

I.- En primer término, y en consonancia con lo anterior, cabría mencionarse el cambio operado en el propio ejercicio profesional, que ha pasado de una situación intimista y casi familiar, representada por la figura del llamado "médico de cabecera", cuyas relaciones con el paciente reposaban sobre un principio de total confianza, a otra situación mucho más despersonalizada, coincidente con la construcción y desarrollo de la Medicina Hospitalaria, con los mayores conocimientos científicos y con el propio proceso de socialización de la Medicina, cuyos avances técnicos han permitido una mayor eficacia en los medios diagnósticos y de tratamiento, no exentos de mayores riesgos, al ser notablemente más agresivos en algunos casos.

De otra parte, un gran número de actos médicos se practican hoy en el seno de los Hospitales, en los que el médico para el paciente suele ser en gran número de casos "un médico", no personalizado, existiendo por consiguiente un cierto alejamiento personal y una relación médicopaciente no basada en la confianza tradicional.

2.- Desde otro punto de vista, el proceso de socialización de la Medicina ha conducido a una cobertura sanitaria prácticamente completa de la población (no habiéndose acompañado siempre de un incremento proporcional de medios y de personal), lo que ha venido a provocar un extraordinario incremento del número absoluto de actos profesionales médicos realizados, con lo que cabe esperar un lógico incremento proporcional en el número de actividades profesionales generadoras de este tipo de demandas, el cual se vería incrementado aún más en aquellos supuestos de masificación del ejercicio profesional, la cual facilitaría la aparición de actos imprudentes o negligentes.

3.- No resulta ajeno a todo lo anterior, el hecho fácilmente comprobable del mayor desarrollo sociocultural, acompañado de un mayor nivel de "conocimientos" médicos de la población en general, facilitada por campañas de difusión o de vulgarización de temas médicos a través de los más diversos medios de comunicación (televisión, radio, prensa).

4.- También cabría citarse un cierto hedonismo que hoy y desde hace años impregna a la sociedad occidental, en la que puede apreciarse un claro rechazo al dolor y al sufrimiento, una menor pasividad ante el infortunio, no aceptándose algunos males, como en épocas pretéritas, como "designios del Cielo" o "calamidades del destino", proyectándose, en ocasiones, aquellos sentimientos bajo la forma de una manifiesta agresividad contra la profesión médica.

Como dice MARTíNEZ-CALCERRADA [7],"frente a una tradicional atonía de entender que cualquier daño o mal producido era inevitable o se carecía de medios de defensa en pos de la reclamación frente al posible autor del mismo, se ha pasado a una situación totalmente contraria no solo de protección del damnificado, sino de la persuasión de este de reaccionar en cualquier caso ante ese resultado perjudicial y atribuirlo siempre a una suerte de mala práctica o actuación -la conocida malpractice del Derecho sajón-, por parte del facultativo, el cual, como ya acontece en otros países de nuestra órbita sociojurídica, adopta un sin fin de cautelas previas antes de decidirse a la intervención profesional demandada".

5.- A mayor abundamiento, los avances técnicos y los mayores conocimientos cientíicos, el mayor perfeccionamiento, en suma, de la Medicina, hacen que el enfermo considere su curación 
no solo como un derecho, que realmente lo es, sino que la curación ha de ser, además, completa y rápida. Si ello no se logra en los términos expresados, se interpreta en algunos casos como un fracaso del médico, debiendo este responder por ello. Como afirma el Magistrado del Tribunal Supremo, SOTO NIETO [8], "los supuestos en que un profesional sanitario puede verse implicado en su responsabilidad se acrecientan en proporción directa con el imparable progreso de la ciencia médica y la renovación incesante de sus técnicas".

6.- De otra parte, el mercantilismo de nuestra época, el conocimiento a través de los medios de comunicación (en ocasiones con una difusión improporcionada) de los casos que llegan a los Tribunales, en los que estos condenan al médico a reparar el daño causado mediante la correspondiente indemnización y el conocimiento por parte del paciente de la existencia de pólizas de seguros que cubren la responsabilidad profesional del médico facilitarían igualmente la presentación de tales demandas judiciales, a lo que ha contribuido también la actitud equívoca y sobre todo comercial de algunos médicos. En este sentido, y a título anecdótico, baste citar que algunos médicos norteamericanos, en cuyo país las demandas de responsabilidad profesional alcanzan cotas verdaderamente alarmantes en algunos Estados, hacen constar en las antesalas de sus consultas que no tienen suscrita póliza de seguro, como medida disuasoria para sus hoy pacientes y potenciales demandantes de mañana.

\section{II.- LA PERITACIÓN MÉDICO-LEGAL.}

\section{EL MÉTODO MÉDICO-LEGAL.}

Una de las transformaciones que ha experimentado la Medicina Legal y Forense en las últimas décadas, y sin duda la de mayor significación práctica, es la nueva dirección impresa al método médico-forense para alcanzar la verdad en su misión pericial.

Con arreglo a los moldes más clásicos, la peritación se reducía a una simple cuestión técnica que la autoridad judicial proponía al perito, limitándose la tarea de este a realizar una serie de investigaciones objetivas, de contenido exclusivamente médico, el resultado de las cuales era expuesto en el correspondiente informe $y$, tras valoración de los datos obtenidos, era concretado el juicio pericial en determinadas conclusiones, a menudo de carácter dubitativo.

Es fácil concebir que ante la escasez de elementos de juicio que se proporcionaba al perito, lo cual derivaba en gran parte de la propia insuficiencia normativa de su método de trabajo, los resultados no habrían de ser todo lo satisfactorios que la recta administración de Justicia requería.

Pero la Medicina Legal y Forense ha evolucionado ampliamente a este respecto, gracias a la incesante labor altruista de sus cultivadores, los que, no resignándose al anterior estado de cosas, dieron una orientación nueva al método pericial, en virtud de la cual la Medicina Legal y Forense ha conseguido una mayor estimación y dignidad clínica, al par que la peritación ha ganado en seguridad y precisión.

Estos nuevos rumbos han dado lugar también a una más estrecha colaboración entre jueces y peritos, beneficiándose grandemente con ello la labor pericial y la Justicia, en tanto que proporcionan amplia y sólida base científica a los informes periciales.

El aspecto más destacado de esta orientación metodológica es, sin lugar a dudas, la valoración por el juicio pericial de las circunstancias extrínsecas de los hechos, como complemento e integración de los datos objetivos. Ello ha creado, como afirmaba DALLA VOLTA [9], una semiótica nueva y uniforme, notablemente amplia y del todo específica de nuestra disciplina. 
Estudiando el caso judicial con arreglo a la metódica de nueva orientación, las conclusiones del perito médico se fundarán, además de sobre datos de personal elaboración, sobre el conjunto de la resultante procesal, dejando de ser un juicio exclusivamente técnico y parcial, para convertirse en la amplia síntesis de un conjunto de elementos de juicio.

La investigación pericial ha salido, pues, de sus estrechos límites primitivos, y las nuevas normas constituyentes de esta metodología propia deben ser consideradas como de estricta y exclusiva pertenencia médico-legal.

La utilidad de dicha orientación metodológica, que bien pudiera calificarse de pluridimensional, es ciertamente extraordinaria. Buena pruebo de ello es que ha entrado en la práctica pericial médica en muchos países $y$, aunque se la designe de diferentes maneras, las directrices que se siguen, vienen presididas por el mismo principio: abarcar la totalidad del complejo médico-legal, analizarlo y después condensarlo en síntesis unitaria.

En nuestro país, la primera y más firme representación de aquella metódica corresponde al Profesor GUIJA MORALES [I0] , al haber establecido la por él denominada metódica funcional de la peritación, por considerar, con muy acertado criterio, que el rendimiento de la capacidad pericial y su aprovechamiento por la Justicia dependen en última instancia del nivel que alcance la "comprensión funcional del suceso", previa vitalización de sus partes y unidad conjunta.

Desde otro punto de vista, cabe señalar que la peritación médico-legal en nuestro país tiene aspectos positivos encomiables y otros que, por el contrario, resultan ya un poco sobrepasados para la época actual. Y es lógico que nos ocupemos de esta faceta aplicativa de la Medicina Legal porque, a nuestro juicio, si el fin último de la Medicina es curar, en el caso de la Medicina Legal y Forense su razón teleológica es el peritar, es resolver los problemas prácticos que el juzgador plantea al perito médico.

Y si profundizamos más en el por qué de este fin, en la razón última de la obligación que todo médico tiene, llegado el caso, de auxiliar a la Justicia actuando como perito en razón de sus conocimientos especiales de índole biológica, llegamos a su verdadera esencia social que podría enunciarse diciendo que la Medicina Legal y Forense es la salvaguarda de los derechos del hombre que vive en sociedad.

Pero a todo ello habría que añadir que, en el momento presente y desde hace años, la peritación médica ha adquirido una diversificación especializada o la creación de verdaderas subespecialidades, que superan netamente las posibilidades del médico perito, contemplado aisladamente.

O dicho de otra forma. Un médico perito capaz y perfectamente preparado, con los medios precisos y dedicado plena y exclusivamente a la Medicina Legal y Forense, muy difícilmente podría abarcar todas aquellas subespecialidades con la efectividad deseable y exigible. Y ello, por razones obvias de tiempo e incluso de extensión de las distintas áreas integradas en la Medicina Legal actual.

De otra parte, para que la peritación médica cumpla acertadamente los fines para los que fue concebida, ha de realizarse ajustándose a normas y principios que constituyen la metodología a que antes se hacía referencia.

Deberá tenerse presente que esta metodología difiere esencialmente de la que de ordinario se sigue en la práctica clínica, condicionado por múltiples y complejos factores, entre los que señalaremos los siguientes: 
La buena disposición, la colaboración sin ánimo de engaño que es dable observar en el ejercicio de la Medicina Clínica, difícilmente la encontraremos en la práctica pericial. En esta, por el contrario, tal como nos viene demostrando la práctica reiteradamente, observaremos con gran frecuencia la simulación de síntomas, síntomas mentidos o alegados, imitados e incluso provocados, los cuales obedecen a intereses no legítimos, dificultando notablemente la actuación pericial.

Asimismo, habrá de tenerse en cuenta que, contrariamente a lo que ocurre en la práctica clínica, en la que se realiza una investigación directa sobre ciertos síntomas y signos presentes en el organismo enfermo, en materia pericial, cuando el perito médico interviene, ordinariamente el factor causal ha desaparecido, siendo su misión reconstruir el pasado a partir de ciertos hallazgos que fueron producidos por la causa provocadora, estableciendo después la obligada relación de causalidad. Se trata, en síntesis, de una investigación a posteriori, lo que conlleva una buena dosis de dificultad añadida.

De otro lado, si bien el algunos casos el factor tiempo juega a favor del médico clínico, habida cuenta de que la evolución de los fenómenos mórbidos pueden ayudarle a precisar el diagnóstico, el médico perito, en muchas ocasiones, tiene en contra aquel factor. Si se trata de un cadáver, porque habrá de evitarse la aparición de los fenómenos destructivos del mismo, que modificarían notablemente el cuadro necrópsico. Si la peritación recayese sobre un sujeto vivo, porque el tiempo haría variar el cuadro inicial, entorpeciendo grandemente la reconstrucción de las condiciones originales.

Otra de las diferencias entre el acto médico y el acto pericial es que el primero de ellos, en ocasiones, basta con suministrar una mera opinión, impresión u orientación clínico-diagnóstica, en tanto que el perito deberá justificar siempre el juicio que emite, apoyándolo en consideraciones científicas y en argumentaciones sólidas y racionalmente deducidas.

Consecuencia de lo últimamente consignado es que el médico perito terminará su actuación, no con el reconocimiento o examen del sujeto, sino que, por el contrario, aquélla quedará plasmada o materializada en uno de los documentos médico-legales, para que así surta efectos ante los Tribunales de Justicia, ante quienes defenderá públicamente las conclusiones que haya elaborado.

\section{EL PERITO MÉDICO.}

El método médico-legal es, ciertamente, algo propio de nuestra ciencia, a la que da su fisonomía específica. Por ello, su ignorancia, la falta de orientación da lugar a que eminentes clínicos, competentes especialistas, sean en la práctica muy mediocres peritos.

El buen perito, siguiendo a GISBERT CALABUIG [I I], resulta de la concurrencia de un conjunto de cualidades:

I.- Posesión de unas condiciones naturales que le marcan con un impulso vocacional y le hacen apto para la función pericial, entre las que se destacan:

* OBJETIVIDAD para la interpretación de las pruebas materiales.

* REFLEXIÓN Y SENTIDO COMÚN para reducir cualquier problema, aún el más complicado, a sus términos más simples. 
* JUICIO para jerarquizar los hechos, subordinar lo secundario a lo principal y correlacionarlos entre sí.

* PRUDENCIA en la elaboración de los dictámenes y, sobre todo, en la formulación de las conclusiones. Como aconsejaban los antiguos tratadistas de nuestra disciplina, el perito debe saber dudar; desconfiar de los signos patognomónicos, pues tanto valor tienen en Medicina Legal la excepción como la regla; defenderse de todo dogmatismo; no aceptar como verdad más que aquello que es admitido y aprobado por todos los magisterios; no creer en la infalibilidad de la técnica y poseer una dosis moderada de escepticismo que, siendo compatible con la eficacia en la labor, permita un sentido crítico de nuestra misión. Como decía BROUARDEL, "la calidad mayor que debe tener el perito no es la extensión de sus conocimientos, sino la noción exacta de lo que sabe y de lo que ignora".

* IMPARCIALIDAD derivada de su formación científica que debe traslucirse en el contenido de sus informes. El médico perito no es en ningún caso perito de las partes, sino de la verdad. Expresará su opinión con tacto, prescindiendo de los epítetos y de los adverbios que den al pensamiento un carácter apasionado, poco adecuado para este tipo de actuaciones.

* VERACIDAD que deberá prevalecer siempre, cualquiera que sean las consecuencias jurídicas y sociales que se deriven de ella.

2.- Formación básica médica, teórica y práctica, así como de las demás ciencias biológicas, cuyo conjunto constituye el vasto dominio de la Medicina Legal.

3.- Conocimientos jurídicos, que le permitan captar exactamente el sentido de las misiones que le sean encomendadas y el alcance de las conclusiones que aporte en sus informes. Señala PALMIERI [12] al respecto, que para ser un buen médico legista es necesario ser, indudablemente, un buen médico, pero esto no basta. Es necesario, además, adquirir una sólida mentalidad jurídica y acertar a repensar jurídicamente los hechos biológicos que han sido adquiridos con la investigación clínica. No se puede ser un buen perito -agrega-, sin ser un buen médico, pero se puede ser un magnífico clínico y un perito mediocre.

Por el contrario, las tres taras psíquicas incompatibles con la misión del perito médico, según SIMONIN [13], son las siguientes:

* el orgullo que ciega.

* la ignorancia, que no hace dudar de nada, y

* la deshonestidad, que envilece y degrada.

Por lo que hace referencia a la primera de ellas, no nos resistimos a reproducir las opiniones del Profesor ROYO-VILLANOVA [I 4], en torno al divismo pericial en Medicina Forense, cuando afirmaba que "en las actividades y actuaciones de que hablamos, como en cualquier otra, hay 
divos encopetados que, ante el público, viven pendientes de sus aplausos, de su lisonja, como si fuera una claque, por desatinadas, ridículas, mezquinas que sean tales expresiones, pero no por eso dejan de ser agradables. Subidos en el pedestal de su engañosa gloria, corrompidos en él, sostenidos por pies de barro, viven con plena entrega al exhibicionismo, en la continua avidez y desazón de su aparatoso orgullo, de su espectacular vanidad. Con ánimo ávido y encendido, deseosos de sobresalir, de descollar, viven estos peritos, estos superperitos, víctimas de su alocada soberbia, carga más que aureola de las pequeñas grandezas humanas, que exige una continua tensión del espíritu y esfuerzos cotidianos para superar a los demás. Esta egorragia, achaque frecuente, muy extendido, exclusivo de los seres humanos, lo sería especialmente entre los doctos, dado que el orgullo, casi inseparable de la sabiduría humana, constituye la mayor pesadumbre, el más terrible enemigo del sabio, su más grave pecado. Los sabios a que nos referimos, vanamente orgullosos de su insegura y pobre ciencia, ávidos de honores y alabanzas, engreídos por la reputación de que gozan en la boca de los aduladores, solo se interesan por las vanas apariencias. Lo que les importa es la reverencia de los demás y no la crítica de los entendidos. Los honores espectaculares más que la verdadera estimación de las inteligencias honestas; las alabanzas de los simples, aunque sean exageradas, aunque suenen a hueco, aunque sean falsas, más que la consideración de los verdaderos sabios".

\section{MARCO NORMATIVO DE LA PERITACIÓN MÉDICA.}

En el ámbito penal, la peritación médica viene regulada en los artículos 456 al 485 de la Ley de Enjuiciamiento Criminal, los cuales, entre otros aspectos, contemplan la existencia de peritos titulares o no titulares, el procedimiento en el nombramiento de los peritos, las incompatibilidades para el desempeño del cargo, las causas de recusación, los honorarios a percibir por los peritos y el contenido o estructura del informe pericial.

En el ámbito civil, el dictamen de los peritos y su regulación, vienen recogidos en los artículos 335 al 352 de la nueva Ley de Enjuiciamiento Civil [15]. Dicho articulado, que se resume en la Tabla I, recoge de forma pormenorizada diferentes aspectos de la prueba pericial.

Asimismo, la nueva Ley de Enjuiciamiento Civil se ocupa de la recusación de los peritos en los artículos 124 al 128 (Tabla 2).

Pese a que el estudio de la prueba pericial en la nueva Ley de Enjuiciamiento Civil escapa del marco asignado a este artículo, requiriendo un estudio pormenorizado y en extensión (tema que ocupará otro artículo de esta revista), estimamos necesario resaltar algunos aspectos del nuevo marco normativo en el que habremos de desarrollar nuestra actividad profesional.

Probablemente sea el dictamen de peritos el medio de prueba cuya fisonomía más ha cambiado con la Ley de Enjuiciamiento Civil, cuyas principales novedades afectan, de una parte, al procedimiento y, de otra, a la consideración del dictamen elaborado por peritos designados por las partes, como prueba a todos los efectos (ESPARZA) [16]. El perito o experto, en opinión del precitado autor, es una persona en la que necesariamente deben concurrir las siguientes tres circunstancias:

I. Ser un tercero procesal, es decir, una persona ajena al proceso concreto en el que intervendrá.

2. Ser una persona que posea, por formación reglada o fruto de la experiencia, conocimientos especializados, científicos, artísticos, técnicos o prácticos.

3. Ser una persona que voluntariamente acepte incorporar dichos conocimientos al proceso, aplicándolos al objeto de la prueba. 
Señala el artículo 340.I de la Ley de Enjuiciamiento Civil que "los peritos deberán poseer el título oficial que corresponda a la materia objeto del dictamen y a la naturaleza de este". Mucho se ha discutido en los últimos meses y en diferentes ámbitos acerca de las cualidades o de los requisitos que habrían de poseer los peritos médicos en sus actuaciones profesionales y mucho se ha debatido también en relación con algunas sentencias aparecidas en estos últimos meses. Es conocida la sentencia de la Sala de lo Contencioso-Administrativo de la Audiencia Nacional en relación con el dictamen pericial emitido por un Experto en Valoración del Daño Corporal, en el caso del fallecimiento de una paciente en un Hospital del Insalud por una septicemia secundaria a un absceso retroperitoneal, del que "no consta tenga la suficiencia técnica, ni la experiencia que da ser un médico especialista".

Otras resoluciones judiciales más recientes, como las dictadas por el Juzgado de lo Penal Número Dos de Gijón o por la Audiencia Provincial de Oviedo, han hecho prevalecer las opiniones de médicos con la misma Especialidad clínica sobre las opiniones emitidas por los Médicos Forenses que intervinieron en aquellos casos de supuesta malpraxis profesional. Sin poner en duda el rigor y la veracidad de los informes periciales emitidos por unos y otros, al desconocer el contenido de los mismos, parece que los Jueces y Tribunales comienzan a cuestionar el papel de los peritos médicos por antonomasia, que no son otros que los Médicos Forenses y los Médicos Especialistas en Medicina Legal y Forense, anteponiendo las opiniones de otros Médicos Especialistas en la materia objeto de examen.

Pese a que del sentido literal del párrafo antes reproducido del artículo 340. I de la Ley de Enjuiciamiento Civil no se desprende que el perito médico deba tener la misma Especialidad que el profesional que hubiere sufrido una demanda por supuesta malpraxis profesional, ha de reconocerse que, en algunos casos, sería necesario y hasta indispensable contar con la opinión de un Médico Especialista en la misma materia clínica para poder dilucidar tal o cual cuestión, eminentemente las de carácter técnico. El informe pericial en estos casos debería ser emitido, en nuestra opinión, de forma conjunta por un profesional de la Especialidad Clínica y por un Médico Forense o Médico Especialista en Medicina Legal y Forense. Estamos convencidos, de otra parte, que el pleno desarrollo de los Institutos de Medicina Legal, con la incorporación en su caso de Especialidades de carácter clínico, podría facilitar la realización de tales dictámenes.

No obstante lo anterior, ha de tomarse también en consideración que en muchos casos de denuncias por malpraxis profesional, lo que está en litigio no suele ser un problema de correcta ejecución de una técnica, ni tampoco el nivel de conocimientos que tuviera el profesional implicado, sino el nivel de diligencia con el que se aplicó aquella técnica o si se pusieron a disposición del paciente, en el momento preciso, todos los medios necesarios, dentro de los disponibles, para conseguir su curación.

No estamos de acuerdo en que para hacer una valoración de esta naturaleza sea exigible siempre estar en posesión del correspondiente Título de la especialidad clínica, bastando en no pocas ocasiones, y con ello no pretendemos trivializar la prueba pericial, con la capacitación que otorga el Título de Licenciado en Medicina. Y decimos esto, a pesar de no compartir el criterio de que el Médico Forense o el Médico Especialista en Medicina Legal y Forense sea experto en todo, incurriéndose así en el denominado Síndrome de Leonardo da Vinci, descrito por el Profesor FIORI [17]. Pero, ies necesario ser Médico Especialista en Cirugía del Aparato Digestivo para saber que ante un síndrome abdominal agudo no se pueden prescribir morfínicos o potentes analgésicos? ies necesario ser Médico Especialista en Obstetricia y Ginecología para saber que una taquicardia fetal, registrada en un cardiotocograma durante el parto, acompañada de la expulsión de meconio, requiere de una actuación diligente para evitar posibles lesiones en el feto? 
Desde otro punto de vista, y por lo que se refiere al artículo 340.2, se reconoce la posibilidad de solicitar dictamen pericial a personas jurídicas legalmente habilitadas para ello, como pudieran serlo, en nuestro caso, las Academias de Medicina, los Colegios Oficiales de Médicos, las Sociedades Científicas, etc. Resulta totalmente esclarecedor el contenido del artículo 340.3, ya que la institución a la que se encargue el dictamen, expresará a la mayor brevedad qué persona o personas se encargarán directamente de prepararlo. Se rompe así la interpretación que de antiguo se venía haciendo respecto de los dictámenes elaborados por algunas de aquellas instituciones, en el sentido de que se trataba de un dictamen o informe de carácter corporativo. Si bien es cierto que la solicitud del dictamen se puede realizar a una persona jurídica (Colegios Oficiales, Academias,...), la ejecución material del mismo corresponderá siempre a una persona física.

Deseamos resaltar, finalmente, el carácter supletorio de la nueva Ley de Enjuiciamiento Civil que, en su artículo 4, señala lo siguiente:

"En defecto de disposiciones en las leyes que regulan los procesos penales, contenciosoadministrativos, laborales y militares, serán de aplicación, a todos ellos, los preceptos de la presente Ley".

Por lo que hace referencia al tema del que nos venimos ocupando, y dado que en la vigente Ley de Enjuiciamiento Criminal no existe norma alguna acerca del procedimiento para la designación judicial de perito, el artículo 34I de la Ley de Enjuiciamiento Civil, que se ocupa de tal cuestión, resultará de aplicación también en el orden procesal penal. El citado artículo dispone lo siguiente:

"Art. 341. I.- En el mes de enero de cada año se interesará de los distintos Colegios Profesionales o, en su defecto, de entidades análogas, así como de las Academias e instituciones culturales y científicas a que se refiere el apartado segundo del artículo anterior el envío de una lista de colegiados o asociados dispuestos a actuar como peritos. La primera designación de cada lista se efectuará por sorteo realizado en presencia del Secretario Judicial, y a partir de ella se efectuarán las siguientes designaciones por orden correlativo".

\section{III.- EL INFORME PERICIAL MÉDICO EN LOS CASOS DE RESPONSABILIDAD PROFESIONAL.}

I.- REGULACIÓN DEL INFORME PERICIAL.

El artículo 478 de la Ley de Enjuiciamiento Criminal, al referirse al informe pericial, señala que este comprenderá, si fuere posible:

$1^{\circ}$. Descripción de la persona o cosa que sea objeto del mismo, en el estado o modo en que se halle. El Secretario extenderá esta descripción, dictándola los peritos y suscribiéndola todos los concurrentes.

$2^{\circ}$. Relación detallada de todas las operaciones practicadas por los peritos y de su resultado, extendida y autorizada en la misma forma que la anterior.

$3^{\circ}$. Las conclusiones que en vista de tales datos formulen los peritos, conforme a los principios y reglas de su ciencia o arte. 
Por su parte, el artículo 485 de la misma Ley señala que "el Juez facilitará a los peritos los medios materiales necesarios para practicar la diligencia que les encomiende, reclamándolos de la Administración pública, o dirigiendo a la Autoridad correspondiente un aviso previo si existieren preparados para tal objeto, salvo lo dispuesto especialmente en el artículo 362".

La nueva Ley de Enjuiciamiento Civil contempla en su artículo 345, la posibilidad de practicar operaciones periciales que requieran el reconocimiento de lugares, objetos o personas, en cuyo caso las partes y sus defensores podrán, únicamente, estar presentes, "si con ello no se impide o estorba la labor del perito y se puede garantizar el acierto e imparcialidad del dictamen", correspondiendo al tribunal decidir lo que proceda en cada caso.

Tal como recoge el artículo 346, que se ocupa de la emisión y ratificación del dictamen, "el perito que el tribunal designe emitirá por escrito su dictamen, que hará llegar al tribunal en el plazo que se le haya señalado. De dicho dictamen se dará traslado a las partes por si consideran necesario que el perito concurra al juicio o a la vista a los efectos de que aporte las aclaraciones o explicaciones que sean oportunas. El tribunal podrá acordar, en todo caso, mediante providencia, que considera necesaria la presencia del perito en el juicio o la vista para comprender y valorar mejor el dictamen realizado".

Es necesario tener presente que, de conformidad con lo previsto en el artículo 347 de la nueva Ley, los peritos tendrán en el juicio o en la vista la intervención solicitada por las partes que el tribunal admita, pudiendo pedir las partes y sus defensores:

I. Exposición completa del dictamen, cuando esa exposición requiera la realización de otras operaciones, complementarias del escrito aportado, mediante el empleo de los documentos, materiales y otros elementos a que se refiere el apartado segundo del artículo 336.

2. Explicación del dictamen o de alguno o algunos de sus puntos, cuyo significado no se considerase suficientemente expresivo a los efectos de la prueba.

3. Respuestas a preguntas y objeciones sobre método, premisas, conclusiones y otros aspectos del dictamen.

4. Respuestas a solicitudes de ampliación del dictamen a otros puntos conexos, por si pudiera llevarse a cabo en el mismo acto y a efectos, en cualquier caso, de conocer la opinión del perito sobre la posibilidad y utilidad de la ampliación, así como del plazo necesario para llevarla a cabo.

5. Crítica del dictamen de que se trate por el perito de la parte contraria.

6. Formulación de las tachas que pudieren afectar al perito.

Continúa el citado artículo 347, contemplando la posibilidad de que "el tribunal podrá también formular preguntas a los peritos y requerir de ellos explicaciones sobre lo que sea objeto del dictamen aportado, pero sin poder acordar, de oficio, que se amplíe, salvo que se trate de peritos designados de oficio conforme a lo dispuesto en el apartado quinto del artículo 339". 


\section{2.- ESTRUCTURA DEL INFORME PERICIAL.}

El informe pericial es uno de los documentos médico-legales, en el que el perito médico, de forma escrita, plasma o materializa su actuación profesional, no bastando con suministrar una mera opinión u orientación, sino que deberá justificar siempre el juicio que emite, apoyándolo en consideraciones científicas y en argumentaciones sólidas y racionalmente deducidas. Dicho informe puede ser emitido a instancia de particulares o bien por acuerdo adoptado por un tribunal.

Este documento médico-legal, según LÓPEZ GÓMEZ y GISBERT CALABUIG [18], quedaría estructurado en las siguientes partes:

1. Preámbulo.

2. Relación y descripción de los objetos acerca de los cuales debe emitirse el informe.

3. Operaciones practicadas.

4. Valoración.

5. Conclusiones.

6. Fórmula final.

Si bien consideramos que la estructura o esquema anterior es válido, en general, para la emisión de un informe pericial, en la práctica, en los casos en los que la peritación recae sobre un supuesto de responsabilidad médica, introducimos ligeras variaciones en aquél para ajustarnos mejor a dichos casos, los cuales pueden recaer, tanto sobre un sujeto vivo, como sobre un cadáver. En síntesis, estructuramos el informe pericial en las partes siguientes:
A. Preámbulo.
B. Parte expositiva.
C. Parte valorativa.
D. Conclusiones.
E. Fórmula final.

\section{A. PREÁmbulo.}

Se iniciaría con el nombre o nombres de los peritos intervinientes, haciendo constar sus títulos y demás datos de carácter personal (DNI, domicilio a efectos de notificaciones, etc.), así como el objeto del mismo y la autoridad o persona que solicita el informe.

En el Preámbulo, estimamos conveniente proceder a la actualización de fórmulas que se han venido utilizando tradicionalmente ("... tiene el honor de emitir el presente dictamen..."), sustituyéndolas por la redacción que ofrece el artículo 335.2 de la nueva Ley de Enjuiciamiento Civil.

En este sentido, tras la exposición de los datos anteriormente mencionados, se consignará que, bajo juramento o promesa de decir verdad, ha actuado con la mayor objetividad posible, tomando en consideración tanto lo que pueda favorecer como lo que sea susceptible de causar perjuicio a cualquiera de las partes, y que conoce las sanciones penales en las que podría incurrir si incumpliere su deber como perito.

\section{B. PARTE EXPOSITIVA.}

Se daría comienzo a esta parte del informe con la elaboración de una relación pormenorizada de toda aquella documentación que se nos hubiera facilitado para su elaboración. Entre aquella documentación se deberá contar con la historia clínica completa, así como otros informes médi- 
cos disponibles, junto a otros documentos, no estrictamente médicos, como pudieran serlo las declaraciones de testigos o del personal sanitario, si las hubiere.

Huelga señalar que, tratándose de una peritación sobre un supuesto de malpraxis profesional, la documentación obrante en la historia clínica resultará de primordial importancia, debiéndose recordar en este punto, en orden a la consecución de la misma, que la Ley General de Sanidad [19] en su artículo 6I establece que la historia clínica "estará a disposición de los enfermos". Asimismo, la Ley de Salud de Andalucía [20] también reconoce en su artículo 6 el derecho de los pacientes "al acceso a su historia clínica".

Por lo que hace referencia a la exposición de la historia clínica, se efectuará siguiendo el orden cronológico de los hechos, reseñando en cada día un resumen de lo que fueron las actividades asistenciales, con expresión de la hora en que se produjeron cada una de ellas, si así consta en la documentación disponible. Estimamos necesario recordar que se debe recoger la totalidad de los datos que figuren en la diversa documentación clínica, tales como hojas de evolución clínica, órdenes de tratamiento, hojas de enfermería, gráficas, resultados analíticos, radiografías, etc., incluyéndolos en la fecha y hora correspondientes, lo que nos permitirá, no solo rehacer la historia clínica, sino establecer una correlación rigurosa de todos los datos clínicos disponibles.

Sin embargo, llegados a este extremo es necesario tomar en consideración que en la inmensa mayoría de las ocasiones (al menos esa es nuestra experiencia), la historia clínica nos llega totalmente desordenada. Nuestra primera labor irá encaminada a la ordenación cronológica de toda la documentación clínica, lo que va a requerir no escaso esfuerzo, máxime si se toma en consideración que para cada día y en cada hora habremos de ir reflejando los datos y comentarios que figuren en los diferentes documentos a que antes se aludía.

Si bien este procedimiento puede llevarse a cabo de forma manual, en el sentido literal del término, resulta aconsejable, al menos para obtener una guía o borrador, el empleo de algún programa informático que permitiera, tras la introducción de los datos, su automática reordenación. En este sentido, el empleo de una hoja del Microsoft Excel proporciona unos buenos resultados.

Habrá casos en los que la parte expositiva finalizará con el resumen de la historia clínica, si bien en otros el epílogo lo constituirán los resultados de la autopsia (clínica o médico-forense) que se hubiese practicado.

En otras ocasiones, cuando el paciente supuestamente perjudicado por una mala praxis profesional estuviere vivo, resultará obligado su reconocimiento por parte del perito, debiendo reflejarse en el informe el estado actual del perjudicado. En este apartado se hará constar el resultado de las exploraciones realizadas, así como los de todos los procedimientos diagnósticos de carácter complementario que se hubieren aplicado. Consecuencia lógica de lo anterior resultará la consignación de aquellas lesiones o defectos que pudieran ser consideradas como secuelas.

\section{PARTE VALORATIVA.}

Estimamos que constituye la parte fundamental del informe pericial $y$, como ya se ha indicado anteriormente, no basta con emitir una mera opinión o impresión sobre los hechos, sino que deberá justificarse de forma razonada el juicio que se emite, apoyándolo en consideraciones científicas y en argumentaciones sólidas y racionalmente deducidas.

Como indica ESPARZA LEIBAR [2 I], "la elaboración del dictamen exigirá para su sostenibilidad posterior, una actividad interna del propio perito, un razonamiento u operación intelectiva y lógica del sujeto que le llevará, aplicando una metodología rigurosa, a alcanzar un resultado 
en relación con el objeto que ha sido sometido a su pericia. Dicho dictamen deberá ser evidentemente, entendido en el sentido común del término, motivado o fundamentado, de tal forma que deberá ser posible para el experto explicar los motivos y razonamientos que le han llevado a concluir en determinado sentido, a la vez que responder a las preguntas a las que eventualmente será sometido".

Recayendo la peritación sobre un supuesto de malpraxis profesional resultará obligado poner de manifiesto la existencia de una falta médica que suponga una infracción del deber objetivo de cuidado en la actuación profesional que se hubiere practicado, determinando, asimismo, la naturaleza y el alcance del perjuicio ocasionado, para finalizar estableciendo el correspondiente nexo o relación de causalidad entre la falta cometida y el perjuicio originado.

Hemos de recordar en estos momentos que la labor pericial del médico, siempre dif́cil, llega a alcanzar cotas de una extraordinaria gravedad cuando aquélla incide en temas de responsabilidad profesional, especialmente, por su trascendencia, los planteados en el ámbito penal.

La prudencia, la objetividad y el rigor que, de ordinario deben acompañar a la actuación pericial médica, se ven notablemente acrecentados en estos casos, dada la presencia, siempre constante, del factor biológico como causa modificadora del nivel de respuesta en cada caso, lo que equivale en la práctica a un análisis individualizado, sin que puedan dictarse pautas de carácter global, que pudieran ser aplicables a la generalidad de los casos.

La valoración de cada acto médico concreto implica una evaluación de todas las circunstancias de tiempo, de lugar y de medios en que se hubiese encontrado el profesional cuya actuación es objeto de discusión. No sería correcto formular evaluación alguna, tomando en consideración datos concluyentes sobre la resolución de aquel caso, pero que sobrevinieron con posterioridad y el profesional, al tiempo de su actuación, no disponía ni podía haber dispuesto de aquéllos. Necesario es analizar las circunstancias en que se encontraba el propio profesional, teniendo en cuenta, no solo los medios a su disposición, justo en el momento de prestar la asistencia, sino también la mayor o menor complejidad que pudiera haber ofrecido el cuadro clínico. Somos conscientes que, sabedores con exactitud de cual fue el resultado final, lo que acontece siempre a posteriori, es fácil dar respuesta a lo que hubiese sido la conducta más acertada.

Sin embargo, nuestra actuación pericial debe tomar en consideración las circunstancias concurrentes al tiempo mismo de haberse prestado la asistencia, viendo si esta se llevó a cabo o no con la oportuna diligencia y analizando, sobre todo, si se aplicaron o pusieron a disposición del paciente todos los medios de que disponía o pudo haber dispuesto el médico al tiempo de prestar aquélla para poder llegar a un diagnóstico y/o tratamiento precisos, que colocaran al paciente en el camino adecuado para obtener su curación, aunque de hecho, en muchos casos, esta no sea alcanzable.

En este sentido, cabe recordar que al valorar la conducta de un profesional, no puede el perito médico entrar en el terreno de lo que pudiéramos denominar como "guerra de escuelas", ni menos aún en el terreno de las hipótesis, como tampoco sería exigible al médico "lo último" que se hubiera descrito como tratamiento para tal o cual proceso, aunque sí es exigible una actualización de sus conocimientos profesionales. Ha de tenerse presente que el médico en la faceta asistencial, primariamente no investiga ni experimenta, limitándose a aplicar sus conocimientos para la resolución de los problemas clínicos planteados. Ante estas consideraciones podríamos afirmar que el mínimo exigible al nivel de sus conocimientos debe alcanzar a lo comúnmente admitido por la generalidad de los profesionales. 
Pero además, aquellos conocimientos y el saber hacer implican que deben ser aplicados con la necesaria y debida diligencia en cada caso, decidiendo cuál ha de ser su actuación más idónea respecto de cada paciente, evitando comportamientos o conductas que pudieran ser consideradas como omisivas, intempestivas o tardías, las cuales resultarían siempre censurables. La dedicación y el amor a la profesión, la entrega sin reservas a lo que se hace, conducirán, a no dudarlo, a encontrar los límites de lo que podría considerarse como una actuación diligente.

No parece quedar duda alguna de que cuando se tiene interés por lo que se está haciendo, y en el ejercicio profesional médico se está obligado a ello, la atención plena del médico debe estar polarizada exclusivamente hacia aquella actividad, evitándose así distracciones, ausencias o insuficiencias, que constituyen la base sobre la que asientan un buen número de demandas.

A aquel grado de conocimiento o saber, y también al saber hacer lo más adecuado en cada caso, se llega a través del continuo esfuerzo para mejorar el nivel de formación profesional mediante el trabajo y el estudio, exigible en la profesión médica, no solo desde el punto de vista legal, sino también desde sus aspectos deontológicos. Puede afirmarse que el aprendizaje y el perfeccionamiento profesional en el médico deben ser de carácter permanente, siéndole exigible también un continuo deber de estudio.

Pero aún así, como ha sido reconocido en reiterada jurisprudencia, no le es exigible, por el contrario, la infalibilidad. El error es siempre posible e incidirá, fundamentalmente, en aquellos casos particulares que revistan una mayor dificultad o complejidad. El error será fácilmente evidenciable en aquellos supuestos en los que el médico sigue unas pautas de comportamiento que la mayoría de sus colegas no habrían aplicado en aquel caso o, por el contrario, ha omitido en su valoración clínica aquellos conocimientos y/o medios técnicos que la mayoría de sus colegas hubiesen puesto en práctica. La situación extrema de lo que venimos analizando en este punto, vendría configurada por el hecho de que con su conducta el médico pusiese de manifiesto una falta de aplicación de conocimientos de carácter general o un defecto del mínimo de habilidad o de destreza en la aplicación de medios materiales o instrumentales.

Queda claro también, por lo que hace referencia a los problemas médicos que revisten una mayor dificultad o complejidad, que el nivel exigible al médico estará en función del mayor o menor grado de especialización de este y a la mayor o menor disponibilidad de medios en uno y otro caso. Ante un determinado cuadro clínico, no se puede esperar un mismo nivel de respuesta del Médico General que ejerce la profesión en un medio rural, de la que debería y tendría que ofrecer un Médico Especialista en un Hospital que contase con suficientes medios personales y materiales.

Señalemos, finalmente, que en muchos casos de la práctica, las dificultades a la hora de valorar la actuación profesional de un médico podrán verse acrecentadas por el extenso número de circunstancias variables que pueden concurrir en un caso dado, siendo nuestra obligación como peritos, la de poner estas de manifiesto, a la vez que argumentar los motivos por lo que no podemos formular una valoración resolutoria. Estos son, probablemente, los casos más difíciles que nos pueden llegar, pero los que ennoblecen aún más a la prueba pericial médica, sin que pueda considerarse que nuestro pronunciamiento forma parte de la denominada "conspiración de silencio", que parece tejerse tras toda demanda por una supuesta malpraxis profesional.

La prueba pericial médica, en estos como en tantos otros casos, aparece como garantía social, debiendo huir siempre de un corporativismo o compañerismo mal entendido. Ello no obsta para que, como ya hemos expresado en otras ocasiones (DOMÍNGUEZ MARTÍNEZ y ROMERO 
PALANCO) [22, 23, 24], ante aquellas especiales circunstancias y dificultades, la reserva se impondrá las más de las veces sobre cualquier pronunciamiento rotundo. De otra parte, y por lo que concierne a la responsabilidad que asumimos desde la disciplina que cultivamos -la Medicina Legal y Forense-, hacia la formación integral del médico, entendemos que la mayoría de las demandas en materia de responsabilidad profesional no se hubiesen planteado, si los profesionales hubiesen sido conocedores de la medida precisa de sus obligaciones, legales y deontológicas, así como de los límites de sus poderes y de sus derechos.

Señalemos, finalmente, que en esta parte valorativa habría que consignar claramente la naturaleza del daño o perjuicio causado, así como su evaluación. En el supuesto de que nuestra actividad pericial recayese sobre un sujeto vivo, habría que analizar de forma pormenorizada todos aquellos aspectos o datos que, de forma habitual, se hacen constar en el parte o informe de sanidad, incluyendo el número de días transcurridos hasta conseguir la curación, el número de días que precisó tratamiento, la naturaleza de esta, el número de días en que estuvo incapacitado para sus ocupaciones habituales, así como la concurrencia de circunstancias que hubieran podido influir en la evolución de las lesiones. De existir secuelas, habría que describirlas, señalando, igualmente, las repercusiones que las mismas pudieran tener sobre su capacidad laboral o sobre su entorno familiar $y / o$ social.

A efectos de facilitar el establecimiento de la cuantía de la indemnización en su caso, y a falta de un baremo específico para evaluar las secuelas en supuestos de malpraxis profesional, lo cual es reclamado cada vez con mayor insistencia por algunos sectores, podrá ofrecerse el resultado de aplicar otros baremos, específicos de otros ámbitos, como pudiera serlo el anexo a la Ley 30/1995, de 8 de noviembre, de Ordenación y Supervisión de los Seguros Privados (BOE, 9-noviembre1995) u otros.

\section{CONCLUSIONES.}

Resultarán del razonamiento seguido en la parte valorativa, resaltándose, en los supuestos que venimos analizando de malpraxis profesional, lo que más interesa al juzgador, que no es otra cosa que la demostración de la falta médica que supuso una infracción del deber objetivo de cuidado, la naturaleza y extensión del perjuicio ocasionado y la relación de causalidad entre ambos.

Como datos adicionales, en algunos casos, deberán señalarse los que figuran habitualmente en los partes de sanidad, a los que antes aludíamos, así como las secuelas que hubieran podido originarse, con su valoración correspondiente.

\section{E. FÓRMULA FINAL.}

Se dará fin al informe escrito con cualquiera de las fórmulas al uso, seguido de la fecha en que se emite el dictamen y de la firma del autor o autores. Estimamos recomendable que la totalidad de las páginas de que consta el informe vayan rubricadas o firmadas por el autor o autores del mismo.

Señalemos, por último, que tras la firma se pueden aportar como Anexos algunos de los documentos que constan en la historia clínica, especialmente aquellos que podrían resultar esclarecedores de tal o cual cuestión en relación con el caso objeto de estudio.

Igualmente, se podrá ofrecer como Anexo la bibliografía que hubiese sido consultada y consignada en el informe, no existiendo inconveniente alguno en que la misma se pudiera ofrecer, alternativamente, como notas a pie de página a lo largo del texto que integra el dictamen. 
TABLA I:

\begin{tabular}{|c|c|}
\hline \multicolumn{2}{|r|}{ LEY DE ENJUICIAMIENTO CIVIL } \\
\hline \multicolumn{2}{|r|}{ DeL DICTAMEN DE PERITOS } \\
\hline Art. 335 & $\begin{array}{l}\text { Objeto y finalidad del dictamen de peritos. Juramento o promesa de actuar con } \\
\text { objetividad. }\end{array}$ \\
\hline Art. 336 & $\begin{array}{l}\text { Aportación con la demanda y la contestación de dictámenes elaborados por peritos } \\
\text { designados por las partes. }\end{array}$ \\
\hline Art. 337 & $\begin{array}{l}\text { Anuncio de dictámenes cuando no se puedan aportar con la demanda o con la } \\
\text { contestación. Aportación posterior. }\end{array}$ \\
\hline Art. 338 & $\begin{array}{l}\text { Aportación de dictámenes en función de actuaciones procesales posteriores a la } \\
\text { demanda. Solicitud de intervención de los peritos en el juicio o vista. }\end{array}$ \\
\hline Art. 339 & $\begin{array}{l}\text { Solicitud de designación de peritos por el tribunal y resolución judicial sobre dicha } \\
\text { solicitud. Designación de peritos por el tribunal, sin instancia de parte. }\end{array}$ \\
\hline Art. 340 & Condiciones de los peritos. \\
\hline Art. 341 & Procedimiento para la designación judicial de perito. \\
\hline Art. 342 & Llamamiento al perito designado, aceptación y nombramiento. Provisión de fondos. \\
\hline Art. 343 & Tachas de los peritos. Tiempo y forma de las tachas. \\
\hline Art. 344 & $\begin{array}{l}\text { Contradicción y valoración de la tacha. Sanción en caso de tacha temeraria o } \\
\text { desleal. }\end{array}$ \\
\hline Art. 345 & Operaciones periciales y posible intervención de las partes en ellas. \\
\hline Art. 346 & Emisión y ratificación del dictamen por el perito que el tribunal designe. \\
\hline Art. 347 & Posible actuación de los peritos en el juicio o en la vista. \\
\hline Art. 348 & Valoración del dictamen pericial. \\
\hline Art. 349 & Cotejo de letras. \\
\hline Art. 350 & Documentos indubitados o cuerpo de escritura para el cotejo. \\
\hline Art. 351 & Producción y valoración del dictamen sobre el cotejo de letras. \\
\hline Art. 352 & Otros dictámenes periciales instrumentales de pruebas distintas. \\
\hline
\end{tabular}

TABLA II:

\begin{tabular}{||c|l||}
\hline \multicolumn{2}{||c||}{ LEY DE ENJUICIAMIENTO CIVIL } \\
\hline \multicolumn{2}{||c||}{ DE LA RECUSACIÓN DE LOS PERITOS } \\
\hline Art. 124 & Ámbito de la recusación de los peritos. \\
\hline Art. 125 & Forma de proponer la recusación de los peritos. \\
\hline Art. 126 & Admisión del escrito de recusación. \\
\hline Art. 127 & Sustanciación y decisión del incidente de recusación. \\
\hline Art. 128 & Costas. \\
\hline
\end{tabular}




\section{BIBLIOGRAFÍA:}

I.- Martínez-Pereda Rodríguez JM: La responsabilidad penal del médico y del sanitario. $2^{a}$ edición. Editorial Colex. Madrid, 1994.

2.- Martínez-Pereda Rodríguez JM: La responsabilidad civil y penal del anestesista. Editorial Comares. Granada, 1995.

3.- Pujol Robinat A, Puig Bausili L: La Medicina Forense ante las denuncias por malpraxis médica. El Médico, 1996; 612: 40-51.

4.- Slawson PF, Guggenhein FG: Psychiatric malpractice: A review of the national loss experience. Amer. J. Psychiat., 1984; 141: 979-981. 5.- Carrasco Gómez JJ: Responsabilidad médica y Psiquiatría. Editorial Colex. Madrid, 1990.

6.- Illich I: Némesis Médica. La expropiación de la salud. Barral Editorial. Barcelona, 1975.

7.- Martínez Calcerrada L: La responsabilidad civil médico-sanitaria. Editorial Tecnos. Madrid, 1992.

8.- Soto Nieto F: Daños derivados de negligencia médica. Tendencia progresiva hacia el establecimiento de un sistema de baremos. La Ley, 1995; 3773: I-9.

9.- Dalla Volta A: Trattato di Medicina Legale. Soc. Editr. Libraria. Milano, 1933.

10.- Guija Morales E: Introducción a la metódica funcional para el diagnóstico médico-forense. Ediciones B. y P. Barcelona, 1950.

II.- Gisbert Calabuig JA: Medicina Legal y Toxicología. 5 a edición. Masson. Barcelona, 1998.

I2.- Palmieri VM: Medicina Forense. Morano. Napoli, 1964.

13.- Simonin C: Medicina Legal Judicial. Reimpresión 2a ed. Española. Editorial Jims. Barcelona, 1973.

14.- Royo-Villanova Morales R: El Divismo pericial en Medicina
Forense. Anales de Medicina Forense de la Asociación Nacional de Médicos Forenses, 1963: 27-30. Reproducido en: Rev. Esp.de Med. Legal, 1996; 76/77: II-15.

15.- Ley I/2000, de 7 de enero, de Enjuiciamiento Civil.- Boletín Oficial del Estado, número 7, de 8 de enero de 2000.

I6.- Esparza Leibar I: El dictamen de peritos en la Ley I/2000, de Enjuiciamiento Civil. Tirant lo Blanch. Valencia, 2000.

17.- Fiori A: II medico legale e la sindrome di Leonardo da Vinci. Riv. Ital. Med. Legale, 1987; 2: 369-38I.

18.- López Gómez L, Gisbert Calabuig JA: Tratado de Medicina Legal. $3^{\mathrm{a}}$ edición. Tomo I. Edit. Saber. Valencia, 1970.

19.- Ley 14/1986, de 25 de abril, General de Sanidad.- Boletín Oficial del Estado $\mathrm{n}^{\circ} 102$, de 29 de abril de 1986.

20.- Ley 2/1998, de 15 de junio, de Salud de Andalucía.- Boletín Oficial de la Junta de Andalucía n⿳0 74, de 4 de julio de 1998.

2I.- Esparza Leibar I: 0b. cit., pág. I4I.

22.- Domínguez Martínez JM, Romero Palanco JL: Accidentes medicamentosos: El asesoramiento pericial en los problemas de responsabilidad médica que con ellos se relacionan. Monografías Médicas Liade. $2^{a}$ Jornadas Toxicológicas Españolas. Gráficas Mora. Madrid, 1975. pp 57-76.

23.- Domínguez Martínez JM, Romero Palanco JL: El médico perito en el juicio oral. Nociones generales acerca de la prueba pericial. Sevilla Médica, 1975; 10/12: 13-22.

24.- Domínguez Martínez JM, Romero Palanco JL: El perjuicio terapéutico y la responsabilidad profesional del médico. In: Deontología. Derecho. Medicina. Edit. por el Colegio Oficial de Médicos de Madrid. Artigrafía SA. Madrid, 1977. pp 605-611. 